\title{
Endocervical polyps in high risk human papillomavirus infections
}

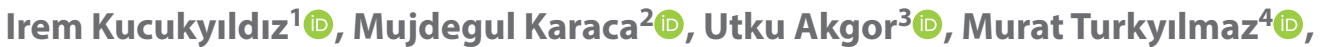 \\ Bekir Keskinkılıc ${ }^{4}$, Fatih Kara ${ }^{4}$, Nejat Ozgul ${ }^{3}{ }^{(0)}$, Murat Gultekin ${ }^{3}(\mathbb{D}$ \\ ${ }^{1}$ Cumhuriyet University School of Medicine, Department of Obstetrics and Gynecology, Sivas, Turkey \\ ${ }^{2}$ Ankara Bilkent City Hospital, Department of Obstetrics and Gynecology, Ankara, Turkey \\ ${ }^{3}$ Hacettepe University Faculty of Medicine, Department of Obstetrics and Gynecology, \\ Division of Gynecologic Oncology, Ankara, Turkey \\ ${ }^{4}$ General Directorate of Public Health, Ministry of Health of Turkey, Ankara, Turkey
}

\begin{abstract}
Objectives: Human papillomavirus (HPV) positive patients with and without endocervical polyps is compared with respect to HPV genotypes and presence of pre-invasive diseases. To our knowledge, this is the first and largest report in the literature examining the endocervical polyps in HPV positive cases.

Material and methods: Clinicopathological data for the first one million screening patients ( $n=1060992)$ from around the entire country during 2015 and 2016 were targeted for this research. Colposcopy, colposcopic surgical diagnostic procedures and final pathology results of 3499 patients with high-risk (HR) HPV-positive were obtained from reference colposcopy centers. Patients with endocervical polyps $(n=243[6.9 \%])$ were accepted as experimental arm while patients without any endocervical polyp ( $n=3256$ [93.1\%]) were regarded as the control group. Age, HPV genotype, Pap smear abnormality, and final pathological results were compared between two groups using Student's t-test and cross-tabulation chi-square test. Results: The incidence of endocervical polyp was found to be $6.9 \%$ in HR HPV-positive women. The most common HPV genotypes observed in both groups were HPV 16 or 18 . Abnormal cytology reports ( $\geq$ ASC-US) were not significantly different between both groups. However, with respect to final pathological diagnosis, patients with endocervical polyp had significantly lower numbers of pre-invasive diseases ( $31.3 \%$ vs $44.2 \% ; p<0.10$ ).

Conclusions: Endocervical polyps may be more common in patients with HR HPV infections. HPV 18 is observed significantly more, in the HR HPV positive endocervical polyp group. Patients with endocervical polyps do not have increased risk for preinvasive cervical diseases.
\end{abstract}

Key words: cervical cancer; colposcopy; human papillomavirus; endocervical polyp; HPV 18; cervical cancer screening

Ginekologia Polska 2022; 93, 1: 7-10

\section{INTRODUCTION}

Endocervical polyps can be described as benign polypoid epithelial overgrowths that arise from the endocervical canal. Their prevalence ranges between $2 \%$ and $5 \%$ among women of reproductive age. With a peak incidence between the ages of 40 and 60 years, they are more commonly seen in the postmenopausal period [1]. With almost all endocervical polyps being benign in character, and the incidence of malignancy varying between $0.1 \%$ and $0.2 \%$, approximately two-thirds of endocervical polyps are asymptomatic, but the most common symptom is abnormal vaginal bleeding [1, 2].
Although the endocervical polyps are common, there are few studies in the published literature. The etiology still has not gained clarity, although chronic inflammation (chronic cervicitis, foreign body reaction), and abnormal local response to estrogen stimulation are the main hypotheses responsible for the formation of cervical polyps [2, 3]. Up to now, there are no reports in the literature evaluating these polyps in high-risk (HR) human papillomavirus (HPV) infections. To our knowledge, this is the first and largest report in the literature examining the endocervical polyps in HPV positive cases.

\section{Corresponding author:}

Irem Kucukyıldız

Cumhuriyet Unıversity School of Medicine, Merkez, Cumhuriyet Üniversitesi, 58140 Imaret/Sivas Merkez/Sivas, Sivas, Turkey

e-mail: iremalyazici@hotmail.com, phone: +905353385603 


\section{MATERIAL AND METHODS}

This study was approved by the Institutional Review Board and all participants gave written general informed consent for use of personal information in health research (Turkısh Public Health Institution No: 23776858-825.03). The experimental arm of the study group consisted of women with a positive HPV test in a national cervical cancer screening program conducted by the Department of Cancer Control and the Public Health Institute of Turkey. Since 2014, Turkey has used HPV DNA for primary screening with extended genotyping and conventional Pap smear to triage HPV-positive cases. Women between the ages of 30 and 65 years are invited for screening by primary health care personnel. Conventional cytology and HPV DNA samples are taken together from each woman at the initial visit to enable cytology testing in those found to be HPV-positive without the need for another visit. For women who are found to be HPV-positive by Hybrid Capture 2 (Qiagen), genotyping is performed using the CLART kit (Genomica). HPV-positive women with abnormal cytology or those positive for HPV 16 or 18 are referred for colposcopy, which is performed free of charge in a post screening diagnostic center (colposcopy centers).

Clinicopathological data for the first one million screening patients ( $n=1060$ 992) from around the entire country during 2015 and 2016 were targeted for this research. Among this screening population, information from patients who were screened and referred to colposcopy centers was retrospectively collected Colposcopy, colposcopic surgical diagnostic procedures (punch biopsy, loop electrosurgical excision procedure, endocervical curette, conization, etc.) and final pathology results of 3499 patients with HR HPV-positive could be obtained from reference colposcopy centers. Patients with endocervical polyps ( $n=243$ [6.9\%]) were accepted as experimental arm, patients without any endocervical polyp ( $n=3256$ [93.1\%]) were regarded as the control group. The parameters collected for comparison of the groups were age, HPV genotype, Pap smear abnormality, and final pathological results. Descriptive epidemiological data and clinicopathological comparisons were evaluated using the Student $t$-test and chi-square test with cross tables. The binary logistic regression test was used for the multivariate analysis. All data were collected and evaluated using Microsoft Excel (Microsoft Corp., Redmond, WA, US) and SPSS 23.0 (IBM Corp., Armonk, NY, US). A p-value less than 0.05 was accepted as significant for statistical comparisons.

\section{RESULTS}

The median age of the patients was 43 years (standard deviation $[S D] \pm 7.58)$ in the endocervical polyp group and 43 years $(S D \pm 8.53)$ in the control arm $(p>0.5)$. Polyps were most commonly seen in women between the ages of 30 to $44(n=138)$. There was no significant difference in patients with and without endocervical polyps with respect to the different age groups (30-44, 45-54, and 55-65 years) (Tab. 1 ). With respect to HPV genotypes, the most commonly encountered HPV in the endocervical polyp group was HPV $16(n=148$ [60.9\%]), followed by HPV $18(n=46$ [18.9\%]), HPV 51 ( $n=22$ [9.1\%]), HPV $31(n=21$ [8.6\%]), and HPV $39(n=19[7.8 \%])$. For patients with no endocervical polyp, the most common were HPV $16(n=2011$ [61.8\%]), followed by HPV $18(n=458$ [14.1\%]), HPV $51(n=382$ [11.7\%]), HPV $31(n=300$ [9.2\%]), and HPV $52(n=258$ [7.9\%]). Among patients with endocervical polyps, $76.1 \%(n=185)$ had HPV 16 or 18 , whereas the remaining $23.9 \%(n=58)$ had HPV types other than HPV 16 and 18. Among patients with no cervical polyp, $72.9 \%(n=2372)$ and $27.1 \%(n=884)$ had HPV 16 or $18(p=0.26)$.

Among the 243 patients with endocervical polyps, cytology results were normal or infection in $49.8 \%$, insufficient in $8.2 \%$, and abnormal in $42 \%$ ( $\geq$ atypical squamous cells

\begin{tabular}{|c|c|c|c|}
\hline & $\begin{array}{l}\text { Patients with } \\
\text { endocervical } \\
\text { polyp } \\
\text { (243 } \\
\text { patients) } \\
\text { (n, \%) }\end{array}$ & $\begin{array}{l}\text { Patients } \\
\text { without } \\
\text { endocervical } \\
\text { polyp } \\
\text { (3256 patients) } \\
\text { (n, \%) }\end{array}$ & p value \\
\hline Age, median & 43 & 43 & \\
\hline \multicolumn{4}{|l|}{ Age intervals } \\
\hline $30-44$ & $138(56.8 \%)$ & $1864(57.2 \%)$ & 0.880 \\
\hline $45-54$ & 78 (32.1\%) & $932(28.6 \%)$ & 0.240 \\
\hline $55-65$ & 27 (11.1\%) & $460(14.1 \%)$ & 0.190 \\
\hline \multicolumn{4}{|l|}{ HR HPV genotypes } \\
\hline 16 or 18 & $185(76.1 \%)$ & 2372 (72.9\%) & \multirow{2}{*}{0.260} \\
\hline Other genotypes & $58(23.9 \%)$ & $884(27.1 \%)$ & \\
\hline \multicolumn{4}{|l|}{ Pap smear } \\
\hline Normal & $22(9.1 \%)$ & $237(7.3 \%)$ & 0.300 \\
\hline ASC-US & 27 (11.1\%) & $411(12.6 \%)$ & 0.490 \\
\hline LSIL & $64(26.3 \%)$ & $983(30.2 \%)$ & 0.200 \\
\hline HSIL & $7(2.9 \%)$ & $86(2.6 \%)$ & 0.820 \\
\hline \multicolumn{4}{|l|}{ Final pathology } \\
\hline Normal & 167 (68.7\%) & $1818(55.8 \%)$ & $<0.001$ \\
\hline CIN1 & $33(13.6 \%)$ & $675(20.7 \%)$ & 0.007 \\
\hline CIN2 & $16(6.6 \%)$ & $269(8.3 \%)$ & 0.350 \\
\hline CIN3 & 27 (11.1\%) & 409 (12.6\%) & 0.500 \\
\hline Cancer & 0 & $85(2.6 \%)$ & 0.011 \\
\hline Total $\geq$ CIN1 & $76(31.3 \%)$ & $1438(44.2 \%)$ & $<0.001$ \\
\hline
\end{tabular}

ASC-US - atypical squamous cells of undetermined significance; CIN - cervical intraepithelial lesions; HPV - human papillomavirus; HR - highrisk; HSIL — high-grade squamous intraepithelial lesion; LSIL — low-grade squamous intraepithelial lesion 
Table 2. Comparison of HPV genotype distributions within different age groups between patients with and without an endocervical polyp

\begin{tabular}{|c|c|c|c|c|c|c|c|c|c|c|c|c|}
\hline \multirow[b]{2}{*}{ Genotypes } & \multicolumn{3}{|c|}{ Ages 30-44 } & \multicolumn{3}{|c|}{ Ages 45-54 } & \multicolumn{3}{|c|}{ Ages 55-65 } & \multicolumn{3}{|l|}{ Total } \\
\hline & $\begin{array}{l}\text { With } \\
\text { polyp, n } \\
\text { (\%) }\end{array}$ & $\begin{array}{l}\text { Without } \\
\text { polyp, n } \\
(\%)\end{array}$ & $\begin{array}{l}p \\
\text { value }\end{array}$ & $\begin{array}{l}\text { With } \\
\text { polyp, } \\
\text { n (\%) }\end{array}$ & $\begin{array}{l}\text { Without } \\
\text { polyp, n } \\
(\%)\end{array}$ & $\begin{array}{l}p \\
\text { value }\end{array}$ & $\begin{array}{l}\text { With } \\
\text { polyp, n } \\
\text { (\%) }\end{array}$ & $\begin{array}{l}\text { Without } \\
\text { polyp, n } \\
\text { (\%) }\end{array}$ & $\begin{array}{l}p \\
\text { value }\end{array}$ & $\begin{array}{l}\text { With } \\
\text { polyp, n } \\
\text { (\%) }\end{array}$ & $\begin{array}{l}\text { Without } \\
\text { polyp, n } \\
\text { (\%) }\end{array}$ & $\begin{array}{l}p \\
\text { value }\end{array}$ \\
\hline HPV 16 & $\begin{array}{l}91 \\
(65.9 \%)\end{array}$ & $\begin{array}{l}1147 \\
(61.5 \%)\end{array}$ & 0.30 & $\begin{array}{l}43 \\
(55.1 \%)\end{array}$ & $\begin{array}{l}551 \\
(59.1 \%)\end{array}$ & 0.490 & $14(51.9 \%)$ & $\begin{array}{l}313 \\
(68 \%)\end{array}$ & 0.080 & $\begin{array}{l}148 \\
(60.9 \%)\end{array}$ & $\begin{array}{l}2011 \\
(61.8 \%)\end{array}$ & 0.79 \\
\hline HPV 18 & $\begin{array}{l}21 \\
(15.2 \%)\end{array}$ & $\begin{array}{l}246 \\
(13.2 \%)\end{array}$ & 0.50 & $\begin{array}{l}18 \\
(23.1 \%)\end{array}$ & $\begin{array}{l}134 \\
(14.4 \%)\end{array}$ & 0.040 & 7 (25.9\%) & 78 (17\%) & 0.230 & $\begin{array}{l}46 \\
(18.9 \%)\end{array}$ & $\begin{array}{l}458 \\
(14.1 \%)\end{array}$ & 0.04 \\
\hline HPV 31 & $\begin{array}{l}15 \\
\text { (10.9\%) }\end{array}$ & $\begin{array}{l}163 \\
(8.7)\end{array}$ & 0.39 & $\begin{array}{l}6 \\
(7.7 \%)\end{array}$ & $93(10 \%)$ & 0.51 & $0(0 \%)$ & $44(9.6 \%)$ & 0.09 & $\begin{array}{l}21 \\
(8.6 \%)\end{array}$ & 300 (9.2\%) & 0.76 \\
\hline HPV 33 & $2(1.4 \%)$ & $50(2.7 \%)$ & 0.38 & $4(5.1 \%)$ & $17(1.8 \%)$ & 0.049 & 1 (3.7\%) & 11 (2.4\%) & 0.67 & $7(2.9 \%)$ & 78 (2.4\%) & 0.64 \\
\hline HPV 35 & $9(6.5 \%)$ & 70 (3.8\%) & 0.10 & $1(1.3 \%)$ & $45(4.8 \%)$ & 0.15 & $0(0 \%)$ & 32 (7\%) & 0.16 & 10 (4.1\%) & $147(4.5 \%)$ & 0.77 \\
\hline HPV 39 & $13(9.4 \%)$ & $127(6.8 \%)$ & 0.25 & $2(2.6 \%)$ & 64 (6.9\%) & 0.14 & $4(14.8 \%)$ & $19(4.1 \%)$ & 0.01 & $19(7.8)$ & $210(6.4)$ & 0.40 \\
\hline HPV 45 & $2(1.4 \%)$ & $54(2.9 \%)$ & 0.32 & $3(3.8 \%)$ & $22(2.4 \%)$ & 0.41 & $0(0 \%)$ & $9(2 \%)$ & 0.46 & $5(2.1 \%)$ & 85 (2.6\%) & 0.60 \\
\hline HPV 51 & $13(9.4 \%)$ & $223(12 \%)$ & 0.37 & $6(7.7 \%)$ & $\begin{array}{l}107 \\
(11.5 \%)\end{array}$ & 0.30 & $3(11.1 \%)$ & $\begin{array}{l}52 \\
(11.3 \%)\end{array}$ & 0.97 & $22(9.1 \%)$ & $\begin{array}{l}382 \\
(11.7 \%)\end{array}$ & 0.21 \\
\hline HPV 52 & 7 (5.1\%) & 156 (8.4\%) & 0.17 & 1 (1.3\%) & $59(6.3 \%)$ & 0.07 & 1 (3.7\%) & $43(9.3 \%)$ & 0.32 & $9(3.7 \%)$ & $258(7.9 \%)$ & 0.02 \\
\hline HPV 56 & 7 (5.1\%) & 111 (6\%) & 0.99 & $6(7.7 \%)$ & $59(6.3 \%)$ & 0.20 & 3 (11.1\%) & 34 (7.4\%) & 0.41 & 16 (6.6\%) & 204 (6.3\%) & 0.78 \\
\hline HPV 59 & $5(3.6 \%)$ & 87 (4.7\%) & 0.57 & $1(1.3 \%)$ & 32 (3.4\%) & 0.30 & 1 (3.7\%) & 31 (6.7\%) & 0.53 & $7(2.9 \%)$ & 150 (4.6\%) & 0.21 \\
\hline HPV 58 & $7(5.1 \%)$ & 95 (5.1\%) & 0.99 & $6(7.7 \%)$ & $42(4.5 \%)$ & 0.20 & 1 (3.7\%) & $37(8 \%)$ & 0.41 & $14(5.8 \%)$ & $174(5.3 \%)$ & 0.78 \\
\hline HPV 68 & $10(7.2 \%)$ & 87 (4.7\%) & 0.170 & $4(5.1 \%)$ & $42(4.5 \%)$ & 0.800 & $2(7.4 \%)$ & $24(5.2 \%)$ & 0.620 & 16 (6.6\%) & 153 (4.7\%) & 0.190 \\
\hline Total & 202 & 2625 & & 101 & 1267 & & 37 & 727 & & 340 & 4619 & \\
\hline
\end{tabular}

of undetermined significance [ASC-US], $n=102$ ). Of those with abnormal cytology findings, 27 (11.1\%) patients had ASC-US, 64 (26.3\%) had low-grade squamous intraepithelial lesion (LSIL), 1 (0.4\%) had ASC-H, 7 (2.9\%) had high-grade squamous intraepithelial lesion (HSIL), and the remaining $3(1.2 \%)$ had atypical glandular cells. These figures were not significantly different when compared with the control arm (Tab. 1). However, when final pathology reports were compared between both groups, patients with endocervical polyps had significantly higher normal pathologies $(68.7 \%$ vs $55.8 \% ; p<0.001$ ) (Tab. 1). Patients with no endocervical polyp had significantly higher numbers of cervical intraepithelial lesions (CIN) grade 1 or greater lesions (44.2\% vs $31.3 \% ; \mathrm{p}<0.001)$.

A separate subgroup analysis was performed comparing HPV genotypes with respect to different age intervals among both groups (Tab. 2). In all age groups, HPV 16 was the dominant and most commonly seen genotype, showing a decreasing prevalence with age and a peak among patients aged between 30 and 44 years old. HPV 18 had a similar pattern of decreasing prevalence with age. There was no significant difference within the different age groups with respect to HPV 16, despite a higher ratio of HPV 16 among patients without an endocervical polyp. HPV 18 was more common in patients with endocervical polyps than in those without endocervical polyps ( $18.9 \%$ vs $14.1 \%$; $p=0.04$ ). HPV 52 was more common in patients without an endocervical polyp than in the group with an endocervical polyp (7.9\% vs $3.7 \% ; p=0.02$ ). HPV 18 was significantly more common in patients with endocervical polyps between the ages of 45 and 54 (23.1\% vs $14.4 \% ; 5.1 \%$ vs $1.8 \%$ ). HPV 39 was also more common in patients with endocervical polyp among those aged between 55 and 65 ( $14.8 \%$ vs $4.1 \%$; $p=0.01$ ).

\section{DISCUSSION}

The prevalence of endocervical polyps ranges between $2 \%$ and $5 \%$ among women of reproductive age, with a peak incidence between the ages of 40 and 60 years. In this study, the incidence of endocervical polyp was found to be $6.9 \%$ in HR HPV-positive women, with a peak incidence between the ages of 30 and 44 years. This is 1.2 to 3 times more compared with the general population. Accordingly, we can hypothesize that endocervical polyps may be more common in patients with HR HPV infections.

When the HR HPV-positive women with endocervical polyps were examined, we found that HPV 16 was the most common, followed by HPV 18, HPV 51, HPV 31, and HPV 39, respectively. For patients without an endocervical polyp, the most common were HPV 16, HPV 18, HPV 51, HPV 31, and HPV 52, respectively. Our findings show that there was no relationship detected between the presence of endocervical polyp and HPV genotypes in women between the ages of 30 and 44 years old. With respect to HPV genotypes, with HPV 18 being observed significantly more, and HPV 52 be- 
ing significantly low in the endocervical polyp group, these 2 HPV types were found to be significantly different in the endocervical polyp group. It is also well known that HPV 18 is commonly detected in adenocarcinomas that usually develop from the endocervical canal [4-6].

With cervical cancer not being detected in any of the women with endocervical polyps, when all HR HPV-positive patients were compared, an endocervical polyp was not found to be significantly associated with a higher risk for preinvasive cervical diseases. Similar to our findings, in a study evaluating 228 women with asymptomatic cervical polyps, invasive cancer was not detected in any of the polyps despite a high rate of cervical cytology abnormalities (29.8\%) [7]. Based on the results of our study, some may hypothesize that endocervical polyps are not associated with increased risk of preinvasive or invasive cervical diseases. However, in contrast to our findings, Chin et al. [8] published a study of nine cases of squamous intraepithelial lesions (SIL) arising in endocervical polyps. They reported the highest incidence of SIL in endocervical polyps to be around 1 in 200. The authors examined 12 smear samples obtained from nine women and found them to be normal in $58.8 \%$ of the patients, ASC-US in $25 \%$ of the patients, and LSIL in $16.7 \%$ of the patients. All patients had a biopsy, which, within the polyps detected, revealed HSIL in four patients and LSIL in the remaining five patients. Based on their results, the authors highlighted the importance of removing the endocervical polyps because of the significant incidence of SIL in endocervical polyps [8]. However, their findings were based on only nine patients. Also, in contrast to their findings, this incidence has been reported in much lower rates $(0.025-0.2 \%)$ in 2 other previous studies $[1,9]$. Our study is the largest series in the published literature and revealed no additional increased risk for preinvasive diseases even in HR HPV positive cases. While patients with an endocervical polyp had significantly lower numbers of CIN1 or greater lesions, none of the patients had cervical cancer. Again similar to our findings, most studies support the notion that there is no clear indication to excise asymptomatic polyps if cytological and colposcopic findings are normal $[7,10,11]$.

Although this study is the first report in the literature investigating the coexistance of HPV positivity and presence of endocervical polyps, the study has some limitations. This study includes a cross-sectional time frame. Long-term follow-up results of the patients with HR HPV positive endocervical polyp are required. In this way, the relationship between endocervical polyps and preinvasive cervical lesions can be further clarified. Molecular and immunohistochemical studies are needed to verify the relationship between HR HPV and endocervical polyps. The adenocarcinoma arising from endocervical polyp background is an important challenge to solve the clinical impression of our data. On the other hand, the retrospective nature of our study is also a definite bias factor. Nevertheless, this study is the first of its kind, and provides important clues regarding endocervical polyps, and may have a particular impact on future researches.

\section{Conflict of interest}

The authors report no conflict of interest.

\section{Financial disclosure}

Authors have no financial interests about the research.

\section{REFERENCES}

1. Aaro LA, Jacobson LJ, Soule EH. Endocervical polyps. Obstet Gynecol. 1963; 21: 659-665, indexed in Pubmed: 14010498.

2. Berzolla CE, Schnatz PF, O'Sullivan DM, et al. Dysplasia and malignancy in endocervical polyps. J Womens Health (Larchmt). 2007; 16(9): 1317-1321, doi: 10.1089/jwh.2007.0408, indexed in Pubmed: 18001188.

3. Schnatz PF, Ricci S, O'Sullivan DM. Cervical polyps in postmenopausal women: is there a difference in risk? Menopause. 2009; 16(3): 524-528, doi: 10.1097/gme.0b013e3181927286, indexed in Pubmed: 19179926.

4. Korucuoglu U, Guler I, Dogan H, et al. Human papillomavirus effect on the development of endometrial polyps. Eur J Gynaecol Oncol. 2015; 36(5): 551-553, indexed in Pubmed: 26513881.

5. Andersson S, Rylander E, Larsson B, et al. The role of human papillomavirus in cervical adenocarcinoma carcinogenesis. Eur J Cancer. 2001; 37(2): 246-250, doi: 10.1016/s0959-8049(00)00376-2, indexed in Pubmed: 11166153.

6. Castellsagué X, Díaz M, de Sanjosé S, et al. International Agency for Research on Cancer Multicenter Cervical Cancer Study Group. Worldwide human papillomavirus etiology of cervical adenocarcinoma and its cofactors: implications for screening and prevention. J Natl Cancer Inst. 2006; 98(5): 303-315, doi: 10.1093/jnci/djj067, indexed in Pubmed: 16507827.

7. Goldshmid O, Schejter E, Kugler D, et al. Is removal of asymptomatic cervical polyps necessary?: histologic findings in asymptomatic Israeli Jewish women. J Low Genit Tract Dis. 2011; 15(4): 259-262, doi: 10.1097/LGT.0b013e318225e8bb, indexed in Pubmed: 21817919.

8. Chin N, Platt AB, Nuovo GJ. Squamous intraepithelial lesions arising in benign endocervical polyps: a report of 9 cases with correlation to the Pap smears, HPV analysis, and immunoprofile. Int J Gynecol Pathol. 2008; 27(4): 582-590, doi: 10.1097/PGP.0b013e31817e0928, indexed in Pubmed: 18753960.

9. Crum CP, Lee KR. Diagnostic Gynecologic and Obstetric Pathology. Elsevier Saunders, Philadelphia 2005: 419-20.

10. Younis MTS, Iram S, Anwar B, et al. Women with asymptomatic cervical polyps may not need to see a gynaecologist or have them removed: an observational retrospective study of 1126 cases. Eur J Obstet Gynecol Reprod Biol. 2010; 150(2): 190-194, doi: 10.1016/j.ejogrb.2010.02.020, indexed in Pubmed: 20206432

11. MacKenzie IZ, Naish C, Rees CMP, et al. Why remove all cervical polyps and examine them histologically? BJOG. 2009; 116(8): 1127-1129, doi: 10.1111/j.1471-0528.2009.02169.x, indexed in Pubmed: 19515151. 